\title{
LA RECEPCIÓN DE LA LITERATURA PORTUGUESA EN LAS REVISTAS DEL INSTITUTO DE CULTURA HISPÁNICA (1948-1955): CUADERNOS HISPANOAMERICANOS, MUNDO HISPÁNICO Y CORREO LITERARIO ${ }^{1}$
}

\author{
THE RECEPTION OF PORTUGUESE LITERATURE \\ IN THE INSTITUTO DE CULTURA HISPÁNICA MAGAZINES \\ (1948-1955): CUADERNOS HISPANOAMERICANOS, \\ MUNDO HISPÁNICO AND CORREO LITERARIO
}

\author{
Javier DOMINGO MARTÍN \\ Universidad Complutense de Madrid \\ domingomartinjavier@gmail.com
}

Resumen: En este artículo, se estudia la presencia de la cultura y literatura portuguesas en las publicaciones periódicas del Instituto de Cultura Hispánica: Mundo Hispánico, Cuadernos Hispanoamericanos y, fundamentalmente, Correo Literario, la más interesante a este respecto. Haremos un catálogo exhaustivo de los contenidos portugueses en el arco de tiempo elegido (1948-1955) y valoraremos cuáles fueron los condicionantes ideológicos y estéticos que determinaron la recepción de la cultura portuguesa, así como el papel que la literatura del país vecino desempeñó en sus páginas.

Palabras clave: Revistas culturales. Mundo Hispánico. Cuadernos Hispanoamericanos. Correo Literario. Instituto de Cultura Hispánica. Cultura. Literatura. Portugal. Estudios Ibéricos.

\footnotetext{
Abstract: This essay aims to study the reception of portuguese culture

${ }^{1}$ Este trabajo se ha realizado durante una estancia de investigación en el Centro de Estudios Comparatistas de la Universidade de Lisboa, realizada bajo la dirección de Ángela Fernandes y en el marco de las Ayudas a la Movilidad para Estancias Breves de Beneficiarios FPU, que financia el Ministerio de Universidades. Número de referencia: 2016/03916.
} 
and literature in "Instituto de Cultura Hispánica" magazines during the years 1948-1955: Mundo Hispánico, Cuadernos Hispanoamericanos and Correo Literario, the most interesating one in this respect. We will catalogue every text of the corpus in order to establish which ideological and aesthetical variables determined the reception of portuguese culture and which function it played in these magazines.

Key Words: Cultural Magazines. Revistas culturales. Mundo Hispánico. Cuadernos Hispanoamericanos. Correo Literario. Instituto de Cultura Hispánica. Culture. Literature. Portugal. Iberian Studies.

\section{PORTUGAL Y ESPAÑA EN EL CONTEXTO EUROPEO DE POSGUERRA}

El final de la Segunda Guerra Mundial modificó radicalmente el peso de las diferentes potencias en el marco internacional. España - aunque neutral durante el conflicto, muy vinculada a las fuerzas derrotadas del Eje- fue uno de los países más perjudicados en este sentido. La presencia e importancia de un movimiento de clara filiación fascista como era Falange, y los visibles rasgos de totalitarismo y represión presentes en el régimen franquista, conllevó el rechazo frontal de muchas de las potencias aliadas. Así sucedió en diferentes foros internacionales como Postdam (1945), la Asamblea General de la ONU, en Londres, de febrero de 1946 - de la que resultó el cierre de las fronteras francesas-, o la exclusión de España de la Alianza Atlántica y de la OTAN, entre otros.

Todo ello conllevó un cambio de orientación en la política internacional del régimen a partir de 1945. Es significativo, pues, el nombramiento de Alberto Martín Artajo como nuevo ministro de Asuntos Exteriores el 20 de julio de 1945. Su carácter más conciliador (Delgado, 1988: 114), así como su vinculación con el catolicismo, lo convertían en una figura que podía revertir esta situación de aislamiento. También vinculado con el ámbito religioso, Joaquín Ruiz-Giménez, embajador en Roma y, a partir de 1951, ministro de Educación, fue otra figura clave en este cambio de orientación. A él se debe en gran medida la creación del Instituto de Cultu- 
ra Hispánica (ICH) en 1946. Se trató de un lavado de cara del Consejo de la Hispanidad, activo desde 1940 y de explícito carácter fascista, mediante la apuesta por la vía cultural como mejor forma de acercamiento a Hispanoamérica ${ }^{2}$. Los ejes ideológicos que vehicularon dicho acercamiento fueron el catolicismo y un marcado anticomunismo; ambos aspectos como interesadas cartas de presentación en el nuevo contexto de la política internacional de la posguerra mundial y la inminente Guerra Fría ${ }^{3}$. Los directores que presidieron la institución fueron figuras claves de la política cultural del Régimen: Joaquín Ruiz-Giménez desde su creación hasta 1948, luego sustituido por Alfredo Sánchez Bella hasta finales de 1956, aunque la directiva del ICH dependía en última instancia del ministerio de Asuntos Exteriores y, específicamente, de la recién creada Dirección General de Relaciones Culturales.

En todo este proceso, Portugal no desempeñó, desde luego, un papel protagonista. No obstante, no dejó de tener una importancia relativa, en relación, sobre todo, con un nuevo iberismo desarrollado durante la década de los 40, a partir de los modelos del iberismo integrista de Ramiro de Maeztu (Defensa de la Hispanidad, de 1934) y António Sardinha (La alianza peninsular, de 1925 en su primera edición española), y al compás de la buena sintonía diplomática entre los dos regímenes totalitarios: Tratado de Amistad y No Agresión firmado el 17 de marzo de 1939 y renovado en 1948, primer encuentro entre los dictadores el 12 de febrero de 1942, creación del Bloque Ibérico ese mismo año y el simbólico nombramiento de Francisco Franco como doctor Honoris Causa de la Universidad de Coímbra en $1949^{4}$. Esta actitud oficialista — que encarnarán algunas instituciones como el Instituto Cultural Iberoamericano de México, antecedente esencial del ICH (Delgado, 1988: 122), y entre cuyos objetivos se situaba el de "vincular estrechamente la vida intelectual de los católicos de Iberoamérica con España y Portugal” (Cabañas Bravo, 1991: 17)—, la

\footnotetext{
${ }^{2}$ Vid. Delgado (1988, 1992).

${ }^{3}$ Son muy significativas las palabras que dirige el director del ICH a Martín Artajo a finales de 1951: "El instituto es - esencialmente - un organismo de política exterior al servicio de la vinculación de España con Hispanoamérica (...) fomentando — sobre bases preexistentes - la creación de un sentimiento de comunidad en los pueblos que deben tener a España como orientadora, rectora y dirigente" (Cabañas Bravo, 1991: 336-337).

${ }^{4}$ No obstante, desde la constitución del Bloque Ibérico, pacto diplomático entre ambas naciones en el contexto de la Segunda Guerra Mundial, hasta el simbólico Honoris Causa de Francisco Franco, son muchas las reticencias de Salazar (Jiménez Redondo, 1993: 190 y ss.).
} 
representan de forma paradigmática António Ferro, Secretario de Propaganda Nacional (SPN) del régimen de Salazar, y Eugenio Montes, director del Instituto Español en Lisboa, agregado cultural de la embajada española $y$, en definitiva, "el gran interlocutor del oficialismo cultural del franquismo en el Portugal salazarista durante década y media" (Rivero Machina, 2016: 714). Pero también en otras figuras más vinculadas al mundo de la cultura: Eugenio d'Ors (dedica tres glosas del Nuevo glosario al integralismo portugués y prologa el volumen de António Ferro Oliveira Salazar. El hombre y su obra), Pedro de Lorenzo (Y al oeste, Portugal, de 1946), Ernesto Giménez Caballero (Amor a Portugal, de 1949; el mismo año de su nombramiento como doctor en Coímbra), Wenceslao Fernández Flórez (traductor de Queirós y prologuista de Perfil de Salazar, de Luís Teixeira), José María Pemán o Adriano del Valle, homenajeado en las Jornadas Poéticas de Sintra en 1952. Todos ellos encarnaron un discurso neoimperialista y católico cercano a los presupuestos más tradicionalistas del $\mathrm{ICH}$ : Portugal y España debían recuperar su papel tutelar en América y en el mundo occidental, y liderar así la regeneración católica ${ }^{5}$.

De forma paralela a estos contactos de un marcado carácter oficialista y propagandístico (por uno y otro lado) hay que situar una serie de iniciativas, muchas de ellas vinculadas a la Universidad de Coímbra, y con un sentido menos dirigido (Rivero Machina, 2016: 287). Así pues, la mejora de la relación entre los países ibéricos - traducida en becas de estudios e investigación - propicia que una serie de jóvenes intelectuales viajen y residan temporalmente en Portugal. A raíz de ello, se convertirán en importantes mediadores culturales desvinculados de la explícita filiación política de sus predecesores ${ }^{6}$ :

Una actitud al margen de la oficialidad en la que ambas comunidades literarias -la portuguesa y la española-establecieron un fluido diálogo

\footnotetext{
${ }^{5}$ Contamos ya con varios trabajos que estudian estas figuras en su faceta lusófila. Son imprescindibles los acercamientos panorámicos de Rivero Machina (2015a, 2016), así como estudios particulares sobre Eugenio d'Ors (Cerdà, 2000), Pedro de Lorenzo (Rivero Machina, 2017a) y la recepción oficial de Pessoa en los 40 (Sáez Delgado, 2018 y 2019; Cerdà, 2005).

${ }^{6}$ Las diferencias dentro de cada agente de este grupo son, sin embargo, notables: véase, por ejemplo, el caso de Joaquín de Entrambasaguas, vinculado al CSIC y otras plataformas del catolicismo tradicionalista, frente al de Ildefonso Manuel Gil, represaliado durante la Guerra Civil, sostenedor de una postura independiente durante la primera posguerra desde su puesto de profesor de instituto y exiliado en la década de los 60 .
} 
poético. Un diálogo basado en traducciones, estancias universitarias, viajes, congresos, epistolarios, intercambios de libros y colaboraciones "cruzadas" que penetró, a su vez, en la construcción de determinadas poéticas personales, como evidencian poemarios como los Poemas ibéricos de Miguel Torga o Vê se vês terras de Espanha de Alberto Serpa (Rivero Machina, 2016: 900).

Se trata, por ejemplo, de Pilar Vázquez Cuesta, becada por el Instituto para la Alta Cultura de Portugal en la Universidad de Coímbra (1946) y difusora de la obra de Miguel Torga; María Josefa Canellada, doctoranda de estancia en el laboratorio de fonética de la Universidad de Coímbra en 1942 y su marido Alonso Zamora Vicente, crítico de Ínsula, que dedicó especial atención a la literatura portuguesa; Joaquín de Entrambasaguas, primer traductor de Pessoa, en 1946, y un importante mediador desde las revistas vinculadas al CSIC que él mismo dirigía; Charles David Rey, autor de Escritores e paisagens de Portugal (de 1942) y La moderna poesía portuguesa (de 1951); Rafael Morales, quien preparó una antología de poesía portuguesa para el número 80 de El Español y editó sendas antologías de Alberto de Serpa y Adolfo Casais Montero para Adonais; y poetas como Ildefonso Manuel Gil: Historia de la literatura extranjera (de 1943), Ensayos sobre poesía portuguesa (de 1948), Medio siglo de lírica portuguesa (de 1952), Dictinio de Castillo-Elejabeytia, profesor de gallego y portugués en la Universidad de Murcia y habitual conferenciante en la Universidad de Coímbra, y Gabino AlejandroCarriedo, del círculo del conocido lusófilo Ángel Crespo, que desarrolló una importancia actividad en torno a la cultura portuguesa en los $50 \mathrm{y}$, con mayor intensidad, a partir de entonces ${ }^{7}$.

Todo ello se traduce en un cierto intercambio de colaboraciones literarias entre ambos sistemas hemerográficos. Publicaron autores españoles en medios portugueses como Acto, Árvore, Bandarra (con subtítulo Artes e Letras Ibéricas), Cadernos do Meio-Día, O Comedio do Porto, Quatro Ventos, Seara Nova, Sísifo, Vértice. Incluso se proyectó una revista portuguesa de un solo número, Cavalo de todas as cores, con sede en Barcelona. Fue una iniciativa de los poetas con mayor presencia efectiva en España por entonces: Alberto de Serpa y João Cabral de Melo e Neto. Publicaron en ella Vinicius de Moraes, Pedro Homem de Mello,

${ }^{8}$ Para todas ellas, vid. Pires (1986) y Rocha (1985). 
José Régio y E. Tormo. En España, hubo presencia de firmas portuguesas en medios literarios como Ágora, Alba, La Calandria, Cisneros, Corcel, Deucalión, Doña Endrina, Espadaña, El Español, La Estafeta Literaria, Sazón, etc.

El acercamiento fue también notable en las revistas de información cultural, así como en las secciones críticas de revistas literarias. No era anómalo que los medios del Sindicato Español de Estudiantes (Haz, Jerarquía, La Hora, Alcalá, Alférez, Laye, Acanto Cultural) incluyeran contenido relativo a Portugal; en algunas ocasiones se dedicaron números monográficos al país vecino, como el número 50 (1942) del suplemento Sí, el número especial de noviembre de 1949 de Mundo Hispánico o el número 65-66 (julio-agosto de 1953) de la revista Índice de Juan Fernández Figueroa, dedicado al fallecimiento del poeta Teixeira de Pascoaes; e incluso algunas muestras de diálogo entre revistas de ambos países: así, la revista Cisneros se declara en diálogo con Atlántico, Cuadernos Hispanoamericanos con Rumo (Rivero Machina, 2016: 810) y Espadaña define su poética en oposición a la de Poesia Nova; otras, en fin, como La Estafeta Literaria, incorpora con regularidad contenido sobre cultura portuguesa.

En las páginas restantes, centraremos nuestro análisis en las revistas que editó el Instituto de Cultura Hispánica: Mundo Hispánico (MH), Cuadernos Hispanoamericanos $(\mathrm{CCHH}) \mathrm{y}$, fundamentalmente, por su mayor interés a este respecto, Correo Literario (CL). Haremos un catálogo exhaustivo de los contenidos portugueses en el arco de tiempo elegido $(1948-1955)^{9}$ y valoraremos cuáles fueron los condicionantes ideológicos y estéticos que determinaron la recepción de la cultura portuguesa, así como el papel que la literatura del país vecino desempeñó en sus páginas

\footnotetext{
${ }^{9}$ Como se ve, no estudiaremos las dos primeras revistas, $\mathrm{CCHH}$ y $\mathrm{MH}$, en su totalidad (la primera se sigue editando en la actualidad y la segunda publicó su último número en el año 1977). En primer lugar, porque fueron los únicos años de publicación de Correo Literario, el caso más significativo de nuestro corpus. En segundo lugar, porque este cambio de década es especialmente interesante, tanto en el ámbito de las relaciones luso-hispánicas (conviven con un protagonismo compartido los dos acercamientos ibéricos descritos más arriba), como en el de la cultura franquista en general: es el ascenso al poder de Joaquín Ruiz-Giménez y la vuelta al centro hegemónico de los intelectuales de Escorial, ahora reconvertidos en comprensivos.
} 


\section{LA LITERATURA PORTUGUESA EN LAS REVISTAS DEL ICH}

\subsection{Cuadernos Hispanoamericanos}

CCHH fue fundada en enero de 1948 con el objetivo inicial de constituir "una réplica a la revista mensual que los exiliados españoles en México publican en la capital mexicana con el título de Cuadernos Americanos" (Instituto de Cultura Hispánica, 1951) ${ }^{10}$. La dirigió en su primera etapa Pedro Laín Entralgo (luego sustituido por Luis Rosales a partir del número 10), y fue su secretario Ángel Álvarez de Miranda hasta su sustitución en febrero de 1949 por Enrique Casamayor. La redacción correspondía al personal del recién creado Seminario de Problemas Hispanoamericanos. Su primer número prometía que los contenidos sobre el arte y la literatura portuguesa iban a ocupar un lugar relevante en el proyecto. Así, Florentino Pérez Embid firmaba un artículo acerca de las "Ideas actuales sobre estilo manuelino y mudejarismo portugués" y se incluía en su sección de Asterisco una nota sobre la revista Rumo. En él, se hablaba del programa de dicha revista, de un marcado nacionalismo: "Revisar, volver a ver las posiciones mentales de la intelectualidad, genuinamente portuguesa (...) Buscar las formas de una cultura específicamente propia para lograr, inmediatamente, una mejor y más exacta convivencia con los otros centros intelectuales de Europa y América" (Anónimo, 1948: 153). Y se recogía la invitación a reforzar los vínculos peninsulares e iberoamericanos:

Rumo dice: “¿Podremos alguna vez dejar de dialogar con España y con las naciones hispanoamericanas?". Y confiesa: "Romper este diálogo sería para nuestra cultura como separar el árbol de las raíces”, más allá de los lazos con la América hispana: "Es nuestra idea y nuestro propósito el dialogar no solo con los países de Hispanoamérica” (Anónimo, 1948: 153).

\footnotetext{
${ }^{10} \mathrm{Su}$ importancia radica en que fue una de las principales plataformas del equipo de falangistas intelectuales tras su aventura en Escorial, junto con Revista en Barcelona y otras revistas ligadas al Sindicato Español de Estudiantes. En ella apareció, por ejemplo, el famoso artículo de Aranguren "La evolución espiritual de los intelectuales españoles en la emigración" (1953). La revista está digitalizada: http://www.cervantesvirtual.com/partes/235792/cuadernos-hispanoamericanos-80 [20/01/2020]
} 
Pese a esta voluntad inicial, son puntuales los artículos sobre literatura portuguesa: en el número 9, Constantino Láscaris daba cuenta de una colección filosófica dirigida por Joaquín de Carvalho desde Coímbra; en el 39, se reseñó la antología preparada por Pilar Vázquez Cuesta para el número 89 de la colección Adonais (de 1952), subrayando especialmente el carácter ibérico del poeta: "Miguel Torga es un poeta ibérico, un poeta que necesita refrescarse en los seis grandes ríos de la Península, caminar por todas las tierras de España y Portugal" (I.A., 1953: 384), y la labor "de comprensión" de la editora (1953: 385); en el n. 66 (junio de 1955) se publicaban "Cuatro romances ibéricos" de Adriano del Valle; y tres números antes José Osório de Oliveira reflexionaba sobre las historias literarias portuguesa y brasileña ${ }^{11}$; en el número 45 , finalmente, se aludía precisamente a esta escasez de atención: "algunas veces tenemos todos un remordimiento de conciencia que se llama Portugal" (J.M.V., 1953: 352).

Fue más frecuente, sin embargo, la información de carácter político sobre el país vecino. El objetivo era subrayar el acercamiento diplomático entre España y Portugal, como puente de acceso a otros pactos internacionales que a lo largo de estos primeros años de los 50 se fueron obteniendo ${ }^{12}$.

Muchos de estos textos se escribieron a propósito de acontecimientos históricos concretos. Así, cuando se firma la Declaración de Salta se incluye en Cuadernos su punto XVIII: "El Hispanoamericanismo reconoce solemnemente los vínculos excepcionales que unen a la comunidad hispanoamericana con España y Portugal en cuanto países forjadores de su personalidad. Ambos estados tendrán cabida, dentro de condiciones especiales, en el seno de la organización hispanoamericana", aunque el crítico disentía de algunas objecciones respecto de la integración del régimen de Franco en la comunidad iberoamericano (Fojo Colmeiro, 1951: 37). Del mismo modo, a propósito del XXV aniversario del régimen portugués, se escribía sobre su inclusión en el Pacto Atlántico del 28 de mayo de 1951 y la necesidad de que fuera acompañado por España:

\footnotetext{
${ }^{11}$ Exclusivamente sobre literatura brasileña había escrito José Luis Cano en los números 7 ("Introducción a la poesía iberoamericana") y número 9 ("La poesía en el Brasil"); Enrique Casamayor en el número 16 (marzo-abril de 1950) reseñó Literatura del Brasil de Lida Besouchet y Newton Freitas.

${ }^{12}$ Fundamentalmente, el Concordato con la Santa Sede y el convenio con Estados Unidos.
} 
"El ingreso de Portugal en el Pacto Atlántico quedaba incompleto si no lo hacía respaldado por España (con quien se hallaba estrechamente vinculada). Razones de geopolítica aconsejaban que la Península entera se involucrara en la defensa de Occidente frente al comunismo" (Barcia Trelles, 1951: 127). Unos números más tarde, se publicó una alabanza al gobierno de Salazar en este mismo sentido: se destacaba el papel cristiano que desempeñaba Salazar, el lugar del imperio portugués en América, así como las relaciones ya establecidas con Franco tras el Bloque Ibérico de 1942: "Fiel a sí mismo, ha apoyado espiritualmente la actitud de Franco" (Horia, 1953: 243) ${ }^{13}$.

\subsection{Mundo Hispánico}

Mundo Hispánico continúa esta línea más política que cultural ${ }^{14}$. La revista se presentaba como

[...] una publicación mensual, de gran formato, en sesenta páginas - muchas de ellas a todo color-, fruto de la colaboración de los más calificados pensadores, escritores, periodistas y artistas de todos los países de habla española o portuguesa. Aspira a reflejar la unidad sustancial de cultura y civilización que informa la vida de los países hispánicos, así como la riqueza y variedad de particularidades que produce en cada uno de dichos países (ICH, 1950).

Su primer número está fechado en febrero de 1948 con el siguiente cuadro directivo: Manuel M. ${ }^{\mathrm{a}}$ Gómez-Gomes (Romley) como director; Manuel Suárez-Caso, redactor jefe, y Raimundo Susaeta como secretario. Alfredo Sánchez Bella presidía el Consejo Editorial. La dirección pasó a Manuel Jiménez Quílez a partir de junio de 1949 (n. $\left.{ }^{\circ} 16\right)$; y en febrero de 1952 (n. ${ }^{\circ} 47$ ) la asume Alfredo Sánchez Bella, con la incorporación del

\footnotetext{
${ }^{13}$ Otros textos de carácter político ya sea sobre Portugal o sobre Iberoamérica en su conjunto: "Política portuguesa del espíritu" (n. ${ }^{\circ}$ ); "La economía del bloque hispano-portugués" (n. 2 ); "Unión continental iberoamericana en defensa de la paz mundial" y "Economía internacional iberoamericana" (n. ${ }^{\circ}$ 3); "Barroquismo y caracterización de Iberoamérica" (5-6); "La comunidad internacional iberoamericana" (n. $\left.{ }^{\circ} 22\right)$ y "El fenómeno nacionalista en Iberoamérica" (n. $\left.{ }^{\circ} 25\right)$.

${ }^{14}$ La revista está digitalizada: http://www.cervantesvirtual.com/partes/739333/mundo-hispanico-la-revista-de-veintitres-paises-buenos-aires-madrid-mexico [20/01/2020].
} 
poeta José García Nieto como secretario.

El lema de la publicación era "La revista de veintitrés países", que incluía los hispanoamericanos, la propia España, Brasil y Portugal. Además, durante su primer año se subrayaban gráficamente aquellos nombres "que en cada número sean recordados o glosados especialmente". Portugal aparece señalado en cuatro ocasiones: números 2 (marzo), 3 (abril), 5 (mayo) y 8 (septiembre). Esto era debido a una serie de artículos de carácter variado que aparecieron en dichos números, con la excepción del segundo: "Lisboa cumplió 800 años", de Luis Méndez Domínguez (n. ${ }^{\circ}$ 3), una crónica de la celebración del VIII Centenario de Lisboa; "Y Lisboa es así", por Luis de la Barga (n. $\left.{ }^{\circ} 5\right)$ y "Por tierras de Portugal", sin firma y con ilustraciones de Thomaz de Mello (n. $\left.{ }^{\circ} 8\right)$.

Además de estas pocas muestras, que apenas continuaron en años posteriores ${ }^{15}$, es significativo el suplemento especial de noviembre de $1949^{16}$, dedicado a la visita de Francisco Franco a Portugal. En portada, figuran los dos dictadores estrechándose la mano y como titular: "España y Portugal se abrazan. El viaje del generalísimo Franco al país luso". El número se abría con un artículo de Ernesto Giménez Caballero sobre "España, Portugal y el mundo hispánico"17. Partiendo de una concepción del arte como propaganda - ya lo había defendido en su Arte y estado (1935) _ , glosaba la teoría de la Alianza Peninsular propugnada por António Sardinha y defendía una unión política ibérica que excluyera las ideologías "masónica y bolchevique" que habían mediado en las relaciones entre ambos países anteriormente. Todo ello con el objetivo de aportar una visión mesiánica de los dos dictadores y su encuentro: "¿Tiene ahora explicación la acogida prodigiosa — casi mística - de Portugal a Franco?" (1949: 4). Luis de Galinsoga, en "La emoción de lo histórico", pintaba un sentimental retrato de Franco, cuyas lágrimas —el artículo arrancaba con esta confesión: "yo he visto titilar en tres ocasiones las lágrimas en los ojos serenos del Caudillo de España durante su estancia en Lisboa" (1949: 6) -

\footnotetext{
${ }^{15}$ Aparecieron algunos textos sobre asuntos muy diversos: por ejemplo, el texto sobre "Fados, violas y guitarras", por Luis de Barga (n. $\left.{ }^{\circ} 19\right)$ o el de Rogerio Pérez sobre "Cavaleiros y forcados portugueses" (n. $\left.{ }^{\circ} 53\right)$.

${ }^{16}$ En la memoria 1947-1951 se alude a este especial como uno de los "dos éxitos para Mundo Hispánico" en el año 1949.

${ }^{17}$ Es preciso recordar que este mismo autor publicó, también en 1949, su libro Amor a Portugal: una loa en alabanza al viaje de Franco al país vecino.
} 
eran símbolo de su bondad y sensibilidad, así como de la trascendencia del acontecimiento histórico. El triunfalista artículo de Eugenio Montes se centra en uno de los actos cumbres del viaje: el nombramiento de Franco como doctor Honoris Causa por Coímbra. Con una clara intención de subrayar la filiación falangista del régimen, se recuerda el deseo de José Antonio de haber estudiado en dicha universidad y se celebra retóricamente el carácter providencial del nombramiento:

Justicia ha sido hecha. Hace trece años una monstruosa confabulación de sectarismos e inepcias le llamó a la noche día; al día, noche; luz a la sombra, sombra a la luz; defensor del Derecho a Negrín, y tirano a Franco. Ahora, espontánea y libremente, en su independencia altiva y su conciencia insobornable, la siete veces secular Universidad de Coímbra, depositaria de ilustres tradiciones y de la gran escuela jurídica cristiana, pone las cosas en su punto; le restituye a las palabras su sentido y lleva a su claustro a nuestro paladín (1949: 9).

Los otros textos, en fin, de Wenceslao Fernández Flórez, Ismael Herraiz, Manuel Vigil y Luis Calvo, subrayaban la lectura oficialista -neoimperialista, ultracatólica y anticomunista - que recorre todo el número y los demás acercamientos de $\mathrm{MH}$ a lo portugués.

\subsection{Correo Literario}

Correo Literario $^{18}$ se ideó con unas pretensiones afines a sus hermanas mayores:

Continuando la batalla iniciada por la revista Resumen para liberar la información inter-hispánica de la tirania, monopolio y tergiversación de las agencias informativas extranjeras al mundo hispánico, Correo Literario debería cumplir la segunda fase liberando la información y creación literaria hispánica de los moldes de estilo e ideología impuestos por París o Nueva York, favoreciendo un meridiano de las letras propio (...) Los hombres hispánicos que profesen actividades literarias y artísticas deben tener un órgano de información y propaganda de su delicado quehacer. Algunos países europeos han hecho un verdadero producto de penetración

${ }^{18}$ La revista está digitalizada: https://www.march.es/storage/bibliodata/teatro/Correo_Literario [20/01/2020]. 
y exportación de sus glorias en el arte y las letras (...) Y, lo que es más exclusivista y grave, han logrado (...) una especie de monstruoso monopolio en la adjudicación de la fama, como otros países han logrado parecido monstruoso monopolio de la información mundial y especialmente de la iberoamericana (ICH, 1950).

La revista es la más tardía de las tres — su primer número es de marzo de 1950 - y es la que tiene menor duración (93 números hasta 1954, más 10 números entre 1954 y 1955 en su etapa barcelonesa). Por su cuadro de dirección pasaron personalidades de tan diferente cuño ideológico como Leopoldo Panero (director n. ${ }^{\circ}$ 1-18 [5-9], Faustino G. Sánchez Marín (subdirector n. ${ }^{\circ}$ 1-18; director n. ${ }^{\circ}$ [5-9] 19-45), Juan Gich (director n. ${ }^{\circ}$ 46-69), Marcelo Arroita-Jáuregui (subdirector n. ${ }^{\circ}$ 70-93) y Juan Ramón Masoliver (director n. ${ }^{\circ}$ II 1-10).

Durante los cuatro años en que se editó en su periodo madrileño, la revista desarrolló los principales puntos de la ortodoxia del Instituto de Cultura Hispánica: la política de la Hispanidad y el catolicismo como puente ideológico con América y Europa. En paralelo a ello, sin embargo, Correo Literario se convirtió en una importante plataforma de difusión del modelo comprensivo defendido por Ridruejo: fundamentalmente, la recuperación de la tradición literaria de preguerra, defensa de la estética social y reivindicación de la literatura escrita en catalán.

Al contrario que Cuadernos y Mundo, la atención hacia lo portugués es aquí mucho más notable. Desaparece la intencionalidad política explícita que sí observamos en las colaboraciones de las otras revistas; consecuencia, en gran medida, de que la responsabilidad de los artículos sobre Portugal corren a cargo de lusófilos mucho más volcados hacia lo literario que hacia lo político. Se trata, fundamentalmente, de Dictinio de Castillo-Elejabeytia (1906-1987), Ildefonso Manuel Gil (1912-2003), Gabino Alejandro Carriedo (1923-1981), además de Adolfo Lizón (19192011), mucho más vinculado con el poder político en cuanto corresponsal de la prensa del movimiento en Lisboa. En calidad de su carácter de mediadores, son firmas habituales de otras revistas del medio siglo: Lizón, por ejemplo, en sus colaboraciones en La Estafeta e Índice ${ }^{19}$.

\footnotetext{
${ }^{19}$ Es significativo, especialmente, el caso de La Estafeta Literaria, pues fue de las pocas que intentó vehicular la información de lo portugués en secciones regulares. Rivero Machina lo ha explicado por su relación con el modelo por antonomasia del género hemerográfico del periódico cultural: $L a$
} 
Así pues, observamos en Correo Literario un proyecto, si bien nunca constituido en sección regular, de crear un espacio propio para lo portugués. Véase, por ejemplo, el listado de las diferentes secciones donde se atendía a la literatura en otras lenguas (ordenadas cronológicamente):

\begin{tabular}{|c|c|c|c|}
\hline Nombre & $\begin{array}{c}\text { Números } \\
\text { en que aparece }\end{array}$ & Autor & $\begin{array}{c}\text { Objeto de } \\
\text { estudio }\end{array}$ \\
\hline Correo de ultramar & $1-9$ & Sin firma & Hispanoamérica \\
\hline Letras portuguesas & $1,13,25$ & $\begin{array}{l}\text { Ildefonso Manuel } \\
\text { Gil y Dictinio de } \\
\text { Castillo-Elejabeytia }\end{array}$ & Portugal \\
\hline $\begin{array}{l}\text { Correo de } \\
\text { Barcelona }\end{array}$ & $\begin{array}{l}14-17,18,27- \\
28,34,37,89\end{array}$ & $\begin{array}{l}\text { Rafael Santos } \\
\text { Torroella }\end{array}$ & Cataluña \\
\hline Literatura catalana & $\begin{array}{l}17-18,20,28, \\
34,47-48,50 \\
53,55,59,61 \\
63,66,69,72- \\
74,88\end{array}$ & $\begin{array}{l}\text { Rafael Santos } \\
\text { Torroella }\end{array}$ & Cataluña \\
\hline $\begin{array}{l}\text { Correo de España y } \\
\text { del mundo [Crónica } \\
\text { de España y del } \\
\text { mundo] }\end{array}$ & $\begin{array}{l}19-28,30-31 \\
33-50,52-53 \\
56\end{array}$ & Varios & $\begin{array}{l}\text { España, Europa } \\
\text { y América }\end{array}$ \\
\hline
\end{tabular}

Gaceta Literaria: "Esta sección lusófila entraba en diálogo con otras como la también esporádica sección 'Correo de Barcelona' en torno a la actualidad cultural en Cataluña - como 'Correo de Lisboa' aparecida en el número 26, del 10 de mayo de 1945-, o las más regulares 'Las provincias en La Estafeta' y 'La Estafeta en el mundo', estas dos presentes desde el primer número. Estas cabeceras, con guiños a la vertiente catalana y portuguesa en el ámbito cultural de la península, recuerdan, inevitablemente a las Gacetas portuguesa y catalana insertas en La Gaceta literaria de Giménez Caballero quince años atrás" (2016: 825). 


\begin{tabular}{|l|l|l|l|}
\hline $\begin{array}{l}\text { A través del } \\
\text { castellano }\end{array}$ & $\begin{array}{l}23-27,29-30, \\
32,34,37\end{array}$ & $\begin{array}{l}\text { Rafael Vázquez } \\
\text { Zamora }\end{array}$ & Europa \\
\hline $\begin{array}{l}\text { Mirador de las } \\
\text { letras europeas }\end{array}$ & $\begin{array}{l}25-26,28-31, \\
33,36-37,39, \\
42-43,45\end{array}$ & $\begin{array}{l}\text { Jesús Sainz } \\
\text { Mazpule }\end{array}$ & Europa \\
\hline $\begin{array}{l}\text { Galeón de la } \\
\text { quincena }\end{array}$ & $\begin{array}{l}25-28,30,32- \\
34\end{array}$ & José Sanz y Díaz & Hispanoamérica \\
\hline $\begin{array}{l}\text { Correo de México } \\
30,34-35,39, \\
57,60,68,56,\end{array}$ & Luis de Santurce & México \\
\hline $\begin{array}{l}\text { Noticias sobre libros } \\
\text { yremios en todo el } \\
\text { mundo }\end{array}$ & $36-31,33-34$, & J. S. & \\
\hline $\begin{array}{l}\text { Cómo son las letras } \\
\text { de... }\end{array}$ & $44-45,47,53$, & Varios & América \\
\hline $\begin{array}{l}\text { Correo fraternal } \\
55\end{array}$ & $82-90,92-93$ & José María & Hispanoamérica \\
\hline
\end{tabular}

Tabla 1

Como es de esperar, lo hispanoamericano ocupa la mayor parte de la atención internacional de Correo. Sin embargo, junto a dos secciones de carácter europeo - "A través del castellano" y "Mirador de las letras europeas"-, nos encontramos con la sola excepción de dos literaturas peninsulares: la literatura catalana, eje del modelo comprensivo a cargo del crítico Santos Torroella, y un incipiente intento de sección portuguesa desde su primer número: "Letras portuguesas", pero que finalmente solo tuvo tres entregas. Del mismo modo, en la sección "Correo de España y 
del mundo" ${ }^{20}$, centrada fundamentalmente en España e Hispanoamérica, lo portugués ocupó un espacio notable no reservado para otras tradiciones ${ }^{21}$ : con dos correos de Coímbra $(26,39)$, dos de Lisboa $(19,24)$ y tres generales de Portugal $(21,42,53)$.

Los datos de distribución de la revista también aportan datos relevantes. En la sección de "Envíos regulares ordenados por el Sr. Vicesecretario General", de la Memoria económica del ICH correspondiente al año 1953, y dejando a un lado los envíos a Hispanoamérica, se ve que Correo Literario se envió, de forma exclusiva, únicamente a Portugal (1), y conjuntamente con Mundo y Cuadernos, a Alemania (3), Italia (1) y Suiza (1). En cuanto a los "Envíos regulares por órdenes de canje de la biblioteca", encontramos que Portugal es el país europeo al que se dirigen más envíos de Correo (7), seguido por Francia (6), Italia (5) e Inglaterra (4); siendo, en todos los casos, la revista con mayor difusión de las tres en el país vecino.

Es significativo, en este sentido, la página cuarta del primer número, pues parece revelar lo que podría haber sido el proyecto inicial en torno al iberismo. En ella, encontramos en primer lugar el texto programático de Juan Aparicio "A la mayoría siempre”, que define las claves de la ortodoxia del Instituto de Cultura Hispánica. En posición central, un texto sobre Valle-Inclán, integrante de la generación del 98, que será la más fácilmente rescatable de ese pasado liberal al que se enfrenta el modelo comprensivo. En los márgenes, dos secciones de voluntad internacional: "Correo de Ultramar", sobre Hispanoamérica, y la efímera "Letras portuguesas". Dicho carácter protagonista se repite en otros lugares. Así, en el número extraordinario 25 (que hacía una suerte de recuento del estado cultural de España y otros países, al hilo del primer año de vida de Correo Literario) se reservó la página 7 para la crítica de obras internacionales: "Mirador de las letras", por Jesús Sainz Mazpule, sobre Europa; "Galeón de la quincena", por José Sanz y Díaz, sobre Hispanoamérica; y "Letras portuguesas", por Dictinio de Castillo-Elejabeytia, sobre Portugal, que recibe, como se ve, un trato diferenciado respecto de lo europeo.

\footnotetext{
${ }^{20}$ Incluyo bajo esta sección también los casos en que el nombre cambió puntualmente a "Crónica de España y del mundo".

${ }^{21}$ La única excepción fue Marruecos y Tánger, por el importante núcleo de escritores españoles residentes allí. Firmaban dichos Correos Abilio Parra, poeta residente en Larache, y Jacinto López Gorge, poeta melillense.
} 
No obstante lo cual, la mayor parte de la crítica sobre literatura portuguesa se publicó fuera de estas secciones. El conjunto, relativamente amplio, ofrece una visión panorámica de diversos aspectos de la cultura portuguesa, con especial atención a la poesía y, en concreto, a los autores jóvenes. Se estudia la obra de los siguientes:

- Críticos y académicos: José María Viqueira Barreiro (n. ${ }^{\circ}$ 5), João Cabral de Melo (n. ${ }^{\circ}$ 15), Lacerda (n. ${ }^{\circ}$ 26), Vieira de Lemos (n. $\left.{ }^{\circ} 31\right)$, Álvaro Ribeiro (n. $\left.{ }^{\circ} 36\right)$

- Poetas: Alberto Serpa (n. $\left.{ }^{\circ} 1\right)$; Vasco de Lima Couto (n. ${ }^{\circ} 1$ ); Taborda de Vasconcelos (n. ${ }^{\circ}$ 1); José Regio (n. $\left.{ }^{\circ} 13\right)$; Leopoldo Araújo (n. $\left.{ }^{\circ} 13\right)$; Francisco Correia das Neves (n. $\left.{ }^{\circ} 25\right)$, Mihai Eminescu, en traducción portugués (n. $\left.{ }^{\circ} 37-38\right)$, Guillermo de la Cruz Coronado (n. $\left.{ }^{\circ} 42\right)$, Antero de Quental (n. $\left.{ }^{\circ} 44\right)$, Teixera de Pascoaes (n. ${ }^{\circ}$ 69). Brasileños: Carlos Drummond de Andrade (n. ${ }^{\circ}$ 64), Henriqueta Lisboa (n. ${ }^{\circ}$ 64), Cecília Meireles (n. ${ }^{\circ} 76$ ), Jorge de Lima (80).

- Narradores: Augusto Navarro (n. ${ }^{\circ}$ 90), Fernando Namora (n. ${ }^{\circ}$ 93; II. n. $\left.{ }^{\circ} 3\right)^{22}$.

- Teatro: Teatro Universitario de Coímbra (n. $\left.{ }^{\circ} 36\right)$.

- Artistas: António-Lino Pires da Viega $\left(n .^{\circ} 2\right)$, Mário de Oliveira (n. ${ }^{\circ}$ 19); José Sobral de Almada Negreiros (n. $\left.{ }^{\circ} 21\right)$.

Además, se reseñan las revistas portuguesas $A$ Serpente (n. $\left.{ }^{\circ} 22\right)$; Acto (n. ${ }^{\circ}$ 13); Portvcale (n. ${ }^{\circ} 43$ ); Sísifo (n. $\left.{ }^{\circ} 29\right) ;$ Bandarra (n. ${ }^{\circ}$ 79), y colaboran dos autores lusos con importantes contactos en España: el poeta Alberto de Serpa, con dos colaboraciones en los números 53 y 55; y Gaspar Simões, en el número $89^{23}$.

Avanzábamos antes que el interés de Correo Literario por lo portugués es muy diferente al estudiado en el caso de $\mathrm{CCHHy} \mathrm{MH}$, de claras

\footnotetext{
${ }^{22}$ Esta reseña de Fernando Namora (en concreto, de la novela Escenas de la vida de un médico), firmada por Cristóbal González de Grau, fue la única inclusión de contenido portugués en los diez números de la etapa barcelonesa.

${ }^{23}$ Este último hace un recuento, previamente publicado en el lisboeta Diario Popular, de las últimas generaciones de escritores portugueses: Fernando Namora, Mario Archer, Cabral, Manuel da Fonseca, Joaquina Ferreira Vinhais, Santana Quintinha, Cabral do Nascimento, Pedro Homem de Melo, Domingos Monteiro, José Ferreira Monte, Victor Matos, entre otros.
} 
raíces fascistas y neoimperialistas. Pero haríamos mejor si habláramos de intereses, pues la literatura del país vecino adquiere diferentes fisionomías en las páginas de $C L$. En primer lugar, Portugal desempeñó una función auxiliar respecto del diálogo ibérico (con Cataluña, fundamentalmente), desarrollado por el modelo comprensivo. En segundo lugar, Portugal y España, enclaves cristianos de Europa, protagonizarían la regeneración del viejo continente, y servirían de importante enlace con Latinoamérica. Esto, que ya aparecía en las visiones fascistas de los años cuarenta, se presenta aquí desligado de cualquier aspiración totalitaria o integrista, en la línea de un catolicismo progresista desarrollado en otros países como Francia, y de la política de la hispanidad del ICH. Finalmente, el descubrimiento de Portugal y su tradición literaria se constituyó en un importante aliado simbólico en el rescate de los escritores liberales de anteguerra, así como de la modernidad estética en general.

\subsubsection{Portugal y Cataluña: el diálogo ibérico}

Se ha escrito ya bastante sobre la reincorporación de la cultura catalana en el proyecto comprensivo, en la que coincidieron diferentes grupos intelectuales y el propio estado: "Los pasos de una política cultural impulsada desde el Estado, relacionada con la cultura catalana e instalada en el engranaje de un programa liberalizador de alcance más vasto" (Gracia, 1993: 90). Así, dicho catalanismo "pasó a ser leído (...) como el camino más corto para la consolidación de un proyecto de europeización", como afirma Jordi Amat (2007: 14), quien también ha detallado los diferentes hitos en esta historia de acercamiento: entre ellos, la presentación de las cartas entre Unamuno y Maragall en La Casa del Libro de Barcelona (30XI-1951), Curso de Extensión de Lengua y Cultura Españolas organizado por la Universidad de Barcelona (III-1952), y, sobre todo, la organización de los Congresos de Poesía con el apoyo de Joaquín Pérez Villanueva (Segovia, 1952; Salamanca, 1953; Santiago de Compostela, 1954). El sistema hemerográfico se hizo eco de este proceso: revistas alejadas de los núcleos comprensivos, como Ateneo y Arbor, pero sobre todo Revista, de Ridruejo, y la universitaria Alcalá. Uno de los objetivos de los Congresos fue, de hecho, crear una revista en lengua catalana que nunca fue autorizada: Monitor de les Artes y de les Lletres.

Portugal en gran medida desempeñó un papel complementario en 
este acercamiento comprensivo. Las crecientes relaciones culturales entre ambos países favorecían la imagen de una península unificada y dialogante. De hecho, el intelectual prototípico del diálogo España-Cataluña, Miguel de Unamuno, encarnaba la misma función respecto de lo portugués.

Así, es frecuente que el crítico de Correo Literario, al ocuparse de lo portugués, subraye especialmente los casos de contacto y el carácter polisistémico de la Península. En sus colaboraciones en la revista Dictinio de Castillo-Elejabeytia, por ejemplo, se centra fundamentalmente en las instituciones e intelectuales mediadoras: así, en "Correo de España y del mundo" se refiere al doctor Lacerda y su laboratorio de fonética en Coímbra (donde, entre otros, realiza sus estudios doctorales Pilar Vázquez Cuesta, traductora de Miguel Torga) (n. ${ }^{\circ}$ 26), reseña obras de autores bilingües en portugués y español: Coímbra: piedra y paisaje, de Guillermo de la Cruz Coronado (n. ${ }^{\circ} 42$ ), e incluso hace propuestas para intensificar las colaboraciones entre ambos sistemas: en el número 36 se refiere al Teatro Universitario de Coímbra y su representación de tres autos de Gil Vicente y propone: "Hemos hablado largamente con el doctor Quintela, y sabemos con cuánta alegría vendría el TEUC a Madrid para trabajar en colaboración con alguna entidad similar española. ¿No sería magnífico, decimos nosotros, una representación de las tres Barcas en el Teatro Español, las dos primeras por los portugueses y las terceras por los españoles?" (1951: 9). En definitiva, Castillo-Elejabeytia, en sus puntuales acercamientos a la literatura portuguesa en $C L$, se revela como un excelente conocedor de la tradición ibérica de la posguerra: "en cuidadas traducciones de Pilar Vázquez Cuesta, de Rafael Morales, de Santos Torroella y otros, pudo el lector español apreciar recientemente y gustar una poesía actualísima y robusta, que es una de las mejores poesías del mundo de hoy" (1953: 18), y un defensor, asimismo, de la unidad cultural peninsular, al margen de implicaciones políticas: "Acaba de aparecer el primer número de la nueva revista poética Sazón, otro alfil del ya complicado ajedrez lírico peninsular" (1951a: 12).

Esta visión es también compartida por los que intervienen en la revista de forma muy puntual. El crítico bajo las siglas A. O., a propósito de la obra pictórica del pintor António-Lino, resalta sobre todo las conexiones históricas de España y Portugal, con ejemplos como Garcilaso, la Galatea de Cervantes, las cantigas, etc. Por todo ello, afirma: "no es extraño, por tanto, que haya un pintor lusitano que venga ahora a España por su solo 
y personal impulso, por su hondo amor hispánico, porque nuestra luz y nuestro arte le llamen imperativos" (1950: 6).

De la presencia portuguesa en el Primer Congreso de Poesía de Segovia también deja constancia $C L$. Se recoge, en concreto, la conferencia impartida por Alberto Serpa, "La vida de los poetas portugueses" (1952: 9), como muestra de la presencia de poetas internacionales en las jornadas ${ }^{24}$. En un texto, por otro lado, que refleja las mismas inquietudes sociales en ambas tradiciones, cuestión ampliamente debatida en el Congreso: "No quieren Mecenas, quieren el pan y el agua ganados con el sudor de su rostro, en trabajos que dejan las manos limpias como las almas y los igualan con los labradores que cuidan su tierra" (1952: 9).

\subsubsection{Portugal y América}

Otras veces, el acercamiento entre ambos países se leyó en clave de aproximación conjunta a Latinoamérica. En este sentido, es significativa la carta abierta de Tomás Salinas ${ }^{25}$, "Iberismo, hispanismo, lusitanismo...", dirigida a Manuel da Silveira Carozo por su artículo "O imperialismo castelhano e eu" publicado en Latinoamérica. En el mismo, defiende un iberismo alejado de cualquier noción imperialista o jerárquica: "De ahí arranca un movimiento que no pretende unificar nada, ni dar jefaturas ni capitanías a nadie, sino que en trato parigual busca afanosamente la amable concordia, la relación mutua entre los afines". Esta amable concordia debe ampliar sus márgenes y acoger toda la hispanidad, forjada históricamente por las naciones peninsulares: "Para ningún espíritu serio puede ofrecerle ni mediana duda que fueron las gentes peninsulares - lusitanas a la cabeza y en vanguardia - las que dieron a luz un continente. Que hoy mismo lo que de aquella venturosa herencia surgió no es simple herencia y transmisión de lo que de Europa fue, sino creación nueva, sobre realidades históricas distintas". Y aborda uno de los problemas debatidos en el I Congreso de Cooperación Internacional que promovió el mismo Instituto de Cultura Hispánica al principio de la década: la aportación de América a Europa. En este sentido, todos los pueblos de la hispanidad, según Salinas, tienen igual

\footnotetext{
${ }^{24}$ Participaron, además, el francés Claude Aubert, el inglés Roy Campbell y el colombiano Eduardo Carranza. Por el lado catalán, asistieron J. V. Foix, Marià Manent y Carles Riba.

${ }^{25}$ Alto cargo del ICH, habitual de sus medios. Ejerció de Secretario de los cursos de Derecho español e hispanoamericano y en 1974 fue Jefe de Conferencias.
} 
responsabilidad y mérito en esta tarea: "Que sean luego hombres lusitanos, brasileños, mexicanos o españoles los abanderados de las distintas causas, tanto nos da. Lo importante es que todas nuestras gentes sigan la bandera de aquel que sepa levantarla con gallardía, con entereza, con originalidad. Menguada sería la suerte de aquel que tuviera ínfulas de imperialismo" (1951: 9).

Refuerza esta visión el texto "La Península, sin influencias", de Gabino Alejandro Carriedo (1953: 12). En él, destaca tanto las conexiones ibéricas oficiales: António Sardinha ("A Aliança peninsular") y Carlos Malheiro Dias ("Exortaçâo á Mocidade"), como las iniciativas jóvenes: presencia de españoles en la revista Bandarra, o de portugueses en Deucalión, Doña Endrina, Ágora, Alba y Sazón. Por todo ello, es optimista: "Ahora, después de tantos años, el camino está nuevamente abierto a las mutuas influencias ibéricas, que es tanto como decir a la influencia propia, y al más justo y desinteresado espíritu de colaboración". Y suscribe, además, el papel que el editorialista de Bandarra reserva a las culturas ibéricas: "en una Europa doliente y que no sabe qué dirección tomar, en una Europa en que los poderosos imperios del siglo XIX (...) entran en franca y evidente descomposición, el bloque ibérico, constituido por Portugal y España, representa, más que una fuerza material, una conquista del espíritu" (1953: 12).

Se daba una solución ibérica a un problema proclamado en numerosas ocasiones a lo largo de la historia de Correo Literario. Dictinio de Castillo-Elejabeytia, precisamente, aludía a ello a propósito de una revista suiza: "Sabemos que Occidente no puede perecer, que los valores evangélicos son eternos y que Europa, la vieja Europa, continuará rigiendo los destinos del mundo, porque de ella se alzan y alzarán las voces redentoras" (1952: 8), aunque en esta ocasión no menciona explícitamente a Portugal.

El afianzamiento de lazos diplomáticos con Hispanoamérica fue sin duda uno de los motores del desarrollo de las Bienales Hispanoamericanas de Arte que organizó el ICH. Correo Literario se convirtió en su primera plataforma de difusión: fue, en palabras de Cabañas Bravo, "la caja de resonancia del certamen" (1991: 91), sobre todo de la primera, comisariada por el entonces también director de la revista, Leopoldo Panero. En la revista se refleja la voluntad inicial de que Portugal desempeñara un papel importante en la misma. Adolfo Lizón es el encargado de subrayar la 
presencia de los artistas portugueses. En el número 19 analiza la figura de Mário de Oliveira: destaca la influencia española y francesa en su obra, así como el aporte rehumanizador de lo español: "Pues si la pintura no es arte deshumanizado, sí es un arte frío y nada afectivo, excepto en los pintores españoles" (1951a: 9). En el 21 analiza la obra de Almada Negreiros: señala su doble ámbito de trabajo, Madrid y Lisboa, y destaca la participación de honor de los portugueses, filipinos y brasileños en la Bienal.

Sobre este último respecto, Lizón coordina una encuesta, "Los pintores portugueses opinan sobre la Bienal Hispanoamericana”, publicada en el número 24. Allí constata la falta de noticias sobre el certamen en el país vecino:

La tonalidad general de los artistas portugueses frente a la Exposición Hispanoamericana es la más completa desorientación. Nadie sabe nada, entre otras razones, porque Correo Literario no llega a las ciudades portuguesas. Ni siquiera a Lisboa. A la Brasileira del Chiado, el café más literario de Lusitania entera, llegaron con mucho jadeo los primeros números. Tres, acaso cuatro. Y se acabó. Ante tal notable desorientación decidi una actuación personal (1951b: 5).

Los encuestados -Francisco d'Avillez, Carlos Botelho, António Lino, Mário de Oliveira, Almada Negreiros - muestran su falta de conocimiento sobre la misma, así como su deseo de asistir. Además, Oliveira subraya el carácter iberoamericano de la misma, y Almada Negreiros afirma que "por peninsularismo — subraya la voz-, estoy seguro de que me aceptarán" (Lizón, 1951b: 5). La encuesta se amplía en el número siguiente, con las opiniones de Guillermo Felipe, Lázaro Lozano y Tom-Tomaz, muy elogioso respecto del apoyo estatal de la Bienal: "La generosidad y el cariño que se dedica en vuestro país a los artistas es innegable. Me refiero, claro, al ángulo de vista estatal. Podrá tener defectos de orientación, pero no desinterés" (Lizón, 1951c: 5).

La Feria del Libro de 1950, que tenía como países invitados a Portugal, México y Francia, ocupó la página doble del número 26. Anteriormente, ya había aparecido una nota sobre la misma, donde se hacía patente la voluntad internacionalista de esta y otras iniciativas oficiales: "Ya en este año, junto a nuestros editores y libreros, aparecen representaciones de Portugal, México y Francia. ¿Se convertirá con el tiempo en internacional? Creemos que ya se está dando vida a este 
propósito. Se piensa y desea en dar paso a Hispanoamérica y países europeos. ¿Podría esto conseguirse aprovechando la oportunidad de algún Congreso Internacional de Editores?" (Anónimo, 1951: 4). En dicha página central, que incluía una encuesta a editoriales españolas, un ensayo de Antonio Covaleda y una entrevista a Julián Pemartín, se reservaba un pequeño espacio para consignar la participación lusa en la Feria, con título "Portugal en la castellana". Allí, se destacaba la importancia del acontecimiento: "La participación de Portugal en nuestra Feria del Libro, uno de los acontecimientos más simpáticos del año, ha merecido justos elogios". Además, se consignaban algunos actos oficiales: la comida con la presencia del Secretario Nacional de Información portugués, Da Costa, así como la conferencia de António Gonçalves Rodrigues "El libro portugués al servicio de la evangelización del Mundo", cuyo título revela la lectura más oficialista del fenómeno ibérico en la posguerra.

\subsubsection{Portugal y España: la recuperación del pasado liberal y la modernidad estética}

Rivero Machina ha estudiado algunos textos críticos cruzados en la década de los 40 y concluye que todos ellos traslucen "el modelo simétrico de espejos enfrentados con que se quiso ver el panorama poético ibérico" (2015b: 170). Rafael Morales, por ejemplo, en su trabajo "Nueva poesía portuguesa" 26 , ve en las estéticas portuguesas contemporáneas un trasunto de la Juventud Creadora española (con maestros compartidos como Dionisio Ridruejo y Miguel Torga); y Victoriano Crémer ve en el grupo Poesia Nova un trasunto de Garcilaso y en la poesía de Novo Cancioneiro un ejemplo equiparable al propio de Espadaña.

Habida cuenta de este modelo de espejos, lo portugués sirvió también como una forma indirecta de recuperar el pasado liberal de la tradición hispánica, quizá el punto del proyecto comprensivo de mayor importancia desde la prehistoria del mismo en Escorial, con el rescate de Antonio Machado por Ridruejo. No deja, pues, de ser significativo que en la sección "Cosas que pasan, cosas que se dicen" del número 29 se destaque la publicación de unos poemas de Miguel Hernández en la revista Sísifo

\footnotetext{
${ }^{26}$ Se puede leer, junto a sus otros textos sobre cultura portuguesa, en la reciente edición de su Prosa crítica (Morales, 2019), a cargo del que esto escribe.
} 
y la próxima aparición de un estudio de Carmen Conde sobre el autor. Se trataba de "Sepultura de la imaginación"; "Desde que el alba quiso ser alba, toda eres"; "Yo no quiero más luz que tu cuerpo ante el mío"; "El lecho, aquella hierba de ayer y de mañana"; "Solo quien ama vuela. Pero, quien ama tanto". Se incluía, además, una nota final: "Hernández é um dos mais significativos Poetas da geração de Lorca. Igual sorte os roubou à vida". En el segundo número Carmen Conde publicó su ensayo "Miguel Hernández Giner, poeta". Además, colaboraban los poetas José Hierro, Manuel Arce, Joaquín de Entrambasaguas y la propia Conde. En el tercer y último número publicaron Pura Vázquez y Manuel Pinillos.

Es el mismo sentido de un artículo de Adolfo Lizón sobre el novelista portugués Fernando Namora (1954: 5-6). De él destaca, fundamentalmente, su carácter neorrealista: "Seduce Fernando Namora por un amor, directo e irrebasable", y por escribir acorde con "el signo histórico de su país", al contrario de la mayoría de los literatos portugueses contemporáneos, en opinión del conservador Lizón. En lo formal, lo relaciona directamente con las nuevas técnicas de los realistas norteamericanos: "En cuanto al estilo, Fernando Namora es, quizá, el novelista peninsular más parecido a los norteamericanos". Referencia que no es de extrañar en este periodo final de Correo Literario, con Marcelo Arroita-Jaúregui en la subdirección, íntimamente ligado al neorrealismo cinematográfico, teatral y novelístico ${ }^{27}$.

Tres números antes, Gabino Alejandro Carriedo había publicado una entrevista al novelista Augusto Navarro. En ella, se destaca su labor de mediador ibérico en la dirección de la revista Bandarra, con firmas españolas como Laguardia, Crespo y Millán; se refiere a algunas revistas españolas que lee con asiduidad (Índice, fundamentalmente, pero también Correo); y reivindica la figura de muchos de los maestros liberales que se defendían de forma explícita desde otros lugares de la revista: Gregorio Marañón, Ortega y Gasset, Pío Baroja, García Lorca, etc. Sin ir más lejos, ese mismo número 90 situaba en portada el artículo "Antonio Machado y aquel niño que yo fui", de Ismael Moreno.

Si Lizón vinculaba la narrativa de Namora con el realismo norteamericano, Castillo-Elejabeytia, al abordar la nueva poesía portuguesa

\footnotetext{
${ }^{27}$ En otro lugar me he ocupado de la vinculación de la revista con el teatro social, a través, fundamentalmente, de las colaboraciones de Alfonso Sastre y José María de Quinto (Domingo Martín, 2017).
} 
(1951b: 7), la inserta en el contexto de la moderna poesía europea. Se refiere a la poesía de Francisco Correia das Neves y a las revistas Nova Alborada, Novo Cancioneiro, O Cavalo de Todas as Cores A Briosa y A Serpente, define algunas de sus características principales, cercanas a la poesía social de los 50 ("el versolibrismo en la forma y el prosaísmo de la lengua coloquial, hoy en boga, en el fondo, con una variada temática y, a veces, la más arrebatada incoherencia”) y establece su genealogía: Sá Carneiro y Pessoa pero, sobre todo, la poesía occidental moderna: Rilke, Eliot, Spender y el surrealismo francés. Portugal podía servir, entonces, tanto para reivindicar figuras de la tradición republicana española, como para revincular el campo español con la historia de la modernidad estética europea.

\section{CONCLUSIONES}

Como muchos otros aspectos de la posguerra española, el iberismo sufrió una serie de cambios notables en el cambio de década. Junto a las posturas oficialistas de la intelectualidad más vinculada al fascismo de los años 30 y a los centros de poder político: Eugenio Montes y Ernesto Giménez Caballero, en el lado español, o António Ferro, en el portugués; surge ya en la década de los 40 un tipo de intelectual cuyo interés hacia Portugal tenía un carácter más estético que político. Nos referimos, por ejemplo, a mediadores como Rafael Morales, Ildefonso Manuel Gil, Dictinio de Castillo-Elejabeytia o Pilar Vázquez Cuesta, y portugueses como Alberto de Serpa y Adolfo Casais Montero.

Ello no significa que se tratara de una acción desinteresada: la faceta lusófila completaba su perfil intelectual, del mismo modo que otros hombres de letras se dedicaban a la crítica de arte (Ricardo Gullón, Luis Felipe Vivanco) o de cine (Marcelo Arroita-Jáuregui, por ejemplo). Era una forma de obtener capital simbólico (por los rasgos de internacionalidad o vanguardismo asociados), así como un modo de mejorar su perfil para la publicación en prensa y revistas: que en muchas ocasiones, como es el caso de Correo Literario, suponía una fuente de ingresos extra. Además, se constituía en una vía de acceso a otro mercado: véase, por ejemplo, la presencia de Ildefonso Manuel Gil en el campo editorial portugués: Huella del linaje (Oporto: Porvcale, 1950), O Inferno de Carlos Seron (Lisboa: Peninsular, 1955), traducción de La moneda en el suelo (Barcelona: Janés, 
1951), así como numerosas colaboraciones en la prensa portuguesa ${ }^{28}$.

El modelo comprensivo fue una inteligente estrategia de campo mediante la cual ciertos sectores descontentos del catolicismo y del falangismo reivindicaron discursos estéticos heterodoxos como vía de promoción personal frente a sus rivales tradicionalistas. Portugal y su cultura no desempeñó, desde luego, un papel importante en dicho proyecto intelectual. Así, atendiendo a las revistas del Instituto de Cultura Hispánica - creado bajo el amparo de Joaquín Ruiz-Giménez, a la postre Ministro de Educación y principal apoyo político de los intelectuales comprensivos-, vemos cómo la presencia del país vecino en las revistas Mundo Hispánico y Cuadernos Hispanoamericanos se limita a subrayar los acercamientos diplomáticos entre ambos estados. La lectura oficialista de los 40, por tanto, es hegemónica en estos medios.

Correo Literario, sin embargo, presenta unas peculiaridades específicas. La revista de anteguerra La Gaceta Literaria dirigida por Giménez Caballero funcionó como modelo de periódico cultural que tenía entre sus pretensiones proporcionar información de las provincias de España, con especial atención a Cataluña y, además, a Portugal. Aunque el proyecto de vehicular regularmente notas y reseñas sobre el país luso apenas quedó esbozado en dos secciones con poco desarrollo, el total de los textos incluidos es suficientemente relevante para aventurar algunas hipótesis sobre cuáles fueron las lecturas desarrolladas sobre la cultura vecina. Así pues, en estrecha relación con el modelo comprensivo que informaba las páginas de Correo Literario, Portugal cumplió una función auxiliar respecto de tres importantes puntos de dicho proyecto. En primer lugar, contribuyó a subrayar el diálogo ibérico que quería reincorporar lo catalán en los centros dominantes de la cultura. Así, se incidía fundamentalmente en los agentes y obras de contacto entre ambos países, y se subrayaba la historia compartida de ambas culturas. En segundo lugar, a Portugal se le asignó un papel parejo respecto de América, y la intervención de las culturas transatlánticas en Europa. España y Portugal, en tanto antiguos imperios cristianos, debían velar por la regeneración del viejo continente, guiando a las jóvenes naciones latinoamericanas. Finalmente, Portugal, cuya literatura se leía en muchas ocasiones como un espejo de la española, se constituyó como un perfecto aliado en la recuperación de los

${ }^{28}$ Datos extraídos de Rivero Machina (2016: 833-834). 
autores heterodoxos españoles del periodo republicano, así como un hito intermedio de las modernas corrientes estéticas europeas, de las cuales España se había alejado en los periodos de la dictadura de mayor autarquía.

\section{REFERENCIAS BIBLIOGRÁFICAS}

A. O. (1950). "El pintor portugués Antonio-Lino". Correo Literario 2, 6. AMAT, J. (2007). Las voces del diálogo. Poesía y política en el medio siglo. Barcelona: Península.

ANÓNIMO (1948). "Rumo. Revista de cultura portuguesa". Cuadernos Hispanoamericanos 1, 152-153.

(1951). "Portugal, México y Francia en nuestra feria". Correo $\mathrm{Li}$ terario 25,4 .

ARANGUREN, J. L. (1953). "La evolución espiritual de los intelectuales españoles en la emigración”. Cuadernos Hispanoamericanos 38, 125.

BARCIA TRELlES, C. (1951). "Política exterior de Portugal en el 25. aniversario de su nuevo régimen". Cuadernos Hispanoamericanos 23, 167-175.

CABAÑAS BRAVO, M. (1991). La Primera Bienal Hispanoamericana de Arte: arte, politica y polémica en un certamen internacional de los años cincuenta. Universidad Complutense de Madrid (tesis doctoral).

CARRIEDO, G. A. (1953). "La península sin influencias". Correo Literario 79,12 .

(1954). "Un conocido novelista portugués en España". Correo Literario $90,12$.

CASTILLO-ELEJABEYTIA, D. (1951a). "Letras portuguesas". Correo Literario 25, 7.

(1951b). "Nueva revista de poesía". Correo Literario 25, 12.

(1951). "Una representación de Gil Vicente, en el castillo de Montemor, por el Teatro Universitario de Coímbra". Correo Literario 36,9 .

(1952). "El manifiesto de Graal". Correo Literario 50, 8.

(1953). “Cecilia Meireles. Poetisa brasileña”. Correo Literario 76, 
18.

CERDÀ, J. (2000). "Eugenio d'Ors y Portugal”. En Actas del Congreso Internacional de historia y cultura en la frontera, M. J. Fernández García \& M. L. Leal (ed.). Cáceres: Universidad de Extremadura. (2005). "Apuntes para la recepción de Pessoa en España (19441960)". Cuadernos Hispanoamericanos 660, 53-66

DELGADO, L. (1988). Diplomacia franquista y política cultural hacia Iberoamérica (1939-1953). Madrid: CSIC.

(1992). Imperio de papel. Acción cultural y política exterior durante el primer franquismo. Madrid: CSIC.

DOMINGO MARTÍN, J. (2017). “Alfonso Sastre y José María de Quinto en las polémicas teatrales del medio siglo: el discurso dramático de Correo Literario (1950-1954)". Anales de Literatura Española 29, 245-263.

FOJO COLMEIRO, A. (1951). "Hermana España”. Cuadernos Hispanoamericanos 22, 35-39.

GRACIA, J. (1993). "Los años cincuenta y la vía española de un catalanismo cultural". Sistema 112, 89-102.

HORIA, V. (1953). "El ejemplo de Oliveira Salazar". Cuadernos Hispanoamericanos 41, 243-244.

I. A. (1953). "El poeta portugués Miguel Torga". Cuadernos Hispanoamericanos 39, 384-385.

INSTITUTO DE CULTURA HISPÁNICA (1951). Memoria de sus actividades en los años 1947-1951 (AECID).

(1954). Memoria de actividades 1953-1954 (AECID).

J. M. V. (1953). "Un iberista en Italia". Cuadernos Hispanoamericanos $45,352-353$.

JIMÉNEZ REDONDO, J. C. (1993). "La política del bloque ibérico: las relaciones hispano-portuguesas (1936-1949)". Mélanges de la Casa de Velázquez 29.3, 175-202.

LIZÓN, A. (1951a). "El pintor Mário de Oliveira". Correo Literario 19, 9. (1951b). "Los pintores portugueses opinan sobre la Bienal Hispanoamericana". Correo Literario 24, 5.

(1951c). "Carta de Lisboa. Lo que opinan en Portugal de la I Bienal Hispanoamericana". Correo Literario 25, 5.

(1954). "Fernando Namora, novelista portugués". Correo Literario 93, 5-6. 
MORALES, R. (2019). Prosa crítica, J. Domingo Martín (ed.). Madrid: Fundación Universitaria Española.

PIRES, D. (1986). Dicionario das revistas literárias portuguesas do século $X X$. Lisboa: Contexto.

RIVERO MACHINA, A. (2015a). "Amores, interpretaciones y miradas. La intelectualidad franquista ante lo ibérico en los años cuarenta". Tonos digital: Revista electrónica de estudios filológicos 29, https:// digitum.um.es/digitum/bitstream/10201/46388/1/Amores\%2c\%20 interpretaciones\%20y\%20miradas.pdf [20/01/2020].

(2015b). "Portugal y la simetría. Victoriano Crémer y Rafael Morales ante el espejo ibérico". Suroeste 5, 167-175.

(2016). Más allá de la posguerra. Poesía y ámbito literario (19391950). Universidad de Extremadura (tesis doctoral).

(2017a). "España en el reflejo portugués. La contemplación del paisaje rayano en Pedro de Lorenzo". En Topografias literarias. El espacio en la literatura hispánica de la Edad Media al siglo XXI, A. Agraz Ortiz y S. Sánchez-Hernández (eds.), 285-292. Madrid: Biblioteca Nueva.

(2017b). "Sanchos contra Quijotes. Un paradigma ibérico contra el Estado Novo y el franquismo". Interlitteraria 22.1, 30-44.

(2018). "La construcción del canon poético contemporáneo entre España y Portugal. La antología de Eugénio de Andrade para $\mathrm{O}$ Comércio do Porto a mediados del siglo XX". Beoiberística II.1, 203-215.

ROCHA, C. (1985). Revistas literárias do século XX em Portugal. Lisboa: INCM.

SÁEZ DELGADO, A. (2018). "Relaciones literarias entre Portugal y España en los años 40: la cultura oficial y la recepción de Fernando Pessoa". Journal of Iberian and Latin American Research 24, 1-14. (2019). "Portugal y España: el siglo Pessoa". Pessoa Plural 16, $92-$ 114.

SALINAS, T. (1951). "Iberismo, hispanismo, lusitanismo". Correo Literario $16,9$.

SERPA, A. (1952). "La vida de los poetas portugueses". Correo Literario $53,9$.

Recibido el 15 de enero de 2020.

Aceptado el 11 de abril de 2020. 